\title{
Environment Storage Materials applied in cold chain logistics Based on the LCA
}

\author{
Guogang $\mathrm{Li}^{1, a}$, Xiaoliang $\mathrm{Xu}^{2, \mathrm{~b}}$ and Ting Yang ${ }^{3, \mathrm{c}}$ \\ ${ }^{1}$ School of Tianjin University of Technology, Tian jin 300384, china \\ ${ }^{2}$ School of Tianjin University of Technology, Tian jin 300384, china \\ ${ }^{3}$ School of Tianjin University of Technology, Tian jin 300384, china \\ agg@163.com, b734793403@qq.com, ${ }^{\mathrm{c}} 1099828185 @ q q . c o m$
}

Keywords: Cold chain logistics, Cold chain transport, Environment storage material, LCA

\begin{abstract}
Having summarized cold chain logistics concept, characteristic of our country and analyzed the refrigerating transportation facilities and means of inside and outside. Describes the relationship between the environment and the application of thermal storage materials research, environmental regenerator material and cold chain logistics process, and application life cycle assessment (LCA) of content, technical framework for applications of thermal storage materials for a full range of analysis, the conclusion that regenerator material environment has a very important role and impact on the sustainable development of cold chain logistics conclusions.
\end{abstract}

\section{Cold chain logistics}

Cold chain logistics concept. At present, according to the latest national standard definition of cold chain logistics in 2012 is: the perishable fresh food in the production, storage, transportation, sales, and to the consumption of each link is always in a prescribed temperature environment, to ensure the quality of cold-chain items, reduce the consumption of cold-chain items logistics activities. The characteristics of cold chain logistics reflect: one is the particularity of object: fresh food are easy to rot; The second is the particularity of working environment: must limit under appropriate low temperature circumstance. The cold chain for food includes[1]:

(1) cryogenic logistics: under $-50{ }^{\circ} \mathrm{C}$ range of applicable temperature preservation.

(2) frozen logistics: in the range of applicable temperature below $18{ }^{\circ} \mathrm{C}$.

(3) Points of logistics: applicable temperature range in $-2{ }^{\circ} \mathrm{C} \sim+2{ }^{\circ} \mathrm{C}$.

(4) Cold storage logistics: in the range of applicable temperature $0{ }^{\circ} \mathrm{C} \sim 10{ }^{\circ} \mathrm{C}$.

(5) other temperature control logistics: in the range of applicable temperature $10{ }^{\circ} \mathrm{C}$ to $25{ }^{\circ} \mathrm{C}$.

By freezing cold chain logistics processing, cold storage, cold storage, transport and distribution, refrigeration sales four aspects[2] (the model as shown in fig.1).

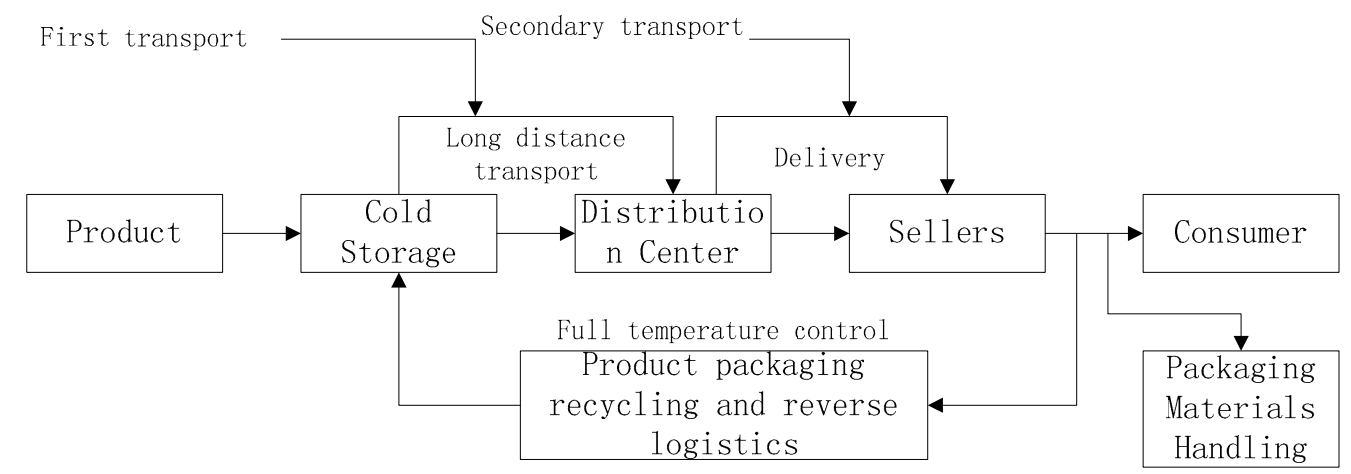

Fig.1 Cold Chain Logistics (Cold Chain) constitute a model

Cold chain logistics transportation facilities and means. At present, the main way of cold-chain transport can be divided into: mechanical refrigerated transport, cold type refrigerated transport and storage type three kinds of refrigerated transport[3]. 
(1) mechanical refrigerated transport

Usually, mechanical refrigerated transport includes refrigerator car, railway refrigerator car and refrigerated container .

(2) Cold refrigerated transport

Cold refrigerated transport is the use of cars or insulation covering the use of insulation materials, insulation measures, the state will have been pre-cooled or frozen products cold way transport.

(3) Storage refrigerated transport

Cold refrigerated transport, is in the insulation inside the car or insulation placement use the package latent heat were cold stored coolant, cooling by coolant carry pairs inside the car's cold, to maintain its storage temperature, you can use different to meet a variety of frozen coolant temperature, cooling capacity should be placed in cold storage depends on the dose and the cooling temperature. Storage media should have a high efficiency, light weight and small volume occupied characteristics. Environmental regenerator material is a new, environmentally friendly, high-quality thermal storage material.

\section{Environment Storage Environment Materials in Cold Chain Logistics}

Many of China's use of environmental materials Storage products cold chain logistics fewer reasons for this phenomenon[4]. First, our cold storage cold truck car less; Second, the country of origin of each charge and cold thermal storage system is not perfect; Third, China's part of the origin of agricultural production operator awareness of cold chain logistics technology is still relatively weak. This concept led to the slow development of cold storage cold chain transportation, technology level is not high. Fourth, environmental research and application of thermal storage materials and inadequate equipment. Environmental Materials as a new technical material, used in our cold storage material is still relatively small, its cold storage mechanism, thermal storage process, the charge / discharge process of cold material changes characteristic of immature, especially its practical application in the production The research has been reported rarely. Regenerator material less postnatal environment on the logistics process and the effect of the product Storage Quality of product research. Environmental regenerator material overcomes many disadvantages of ice storage material can be used as a substitute for ice storage materials.

\section{Life Cycle Assessment (LCA )}

The basic concept of LCA. LCA is a method used to estimate the capacity of the environment, which is a summary and evaluation of a product systems of all inputs and outputs and the potential environmental impact caused by the way in the whole of their life cycle, but also the opportunity to determine the development and evaluation of environmental impact approach[5].

LCA first identify and quantify consumption and environmental release of the entire life cycle stages of energy and matter, and then evaluate the impact of these consumption and release to the environment, and finally identify and evaluate opportunities to reduce these impacts .LCA emphasize the system under study including ecological balance, aspects of human health and resource consumption, etc., environmental impact[5,6].

Technical framework of LCA. LCA common technical framework SETAC (Society of Envi-ronmental toxicology and chemistry) model to describe the triangle as shown[7]. 


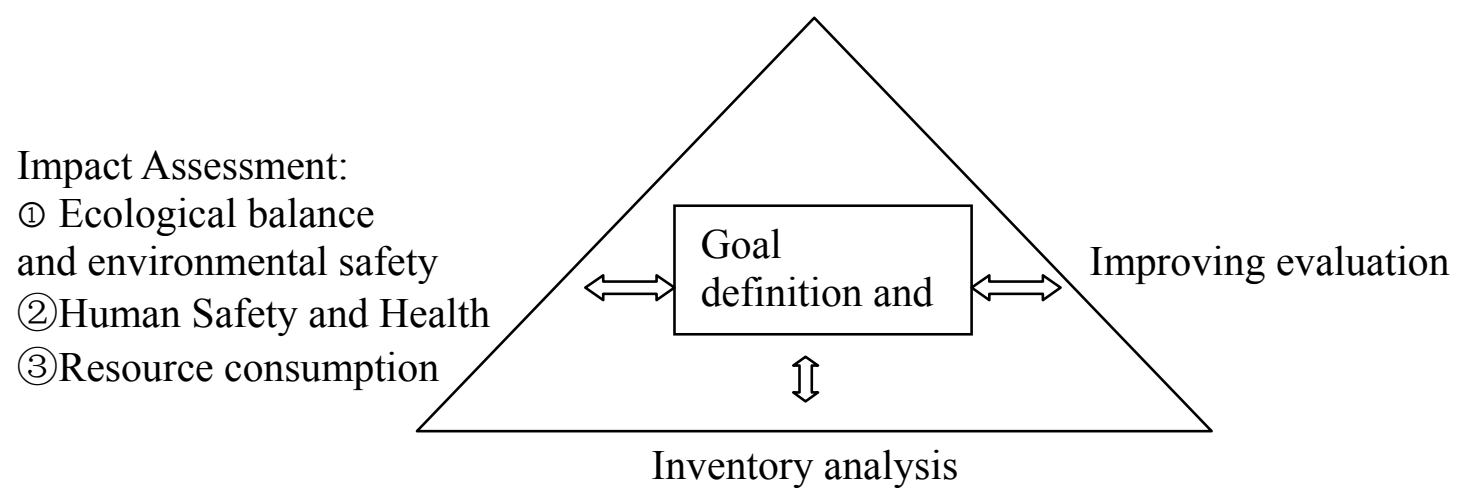

Fig.2 LCA technology framework

Determine the objectives and scope of the study: to determine the purpose and scope of the study, the establishment of functional blocks, the process of establishing procedures to ensure the quality of research[7,8].

Inventory analysis: quantification and evaluation of research products, processes or activities in resource and energy use and environmental release process throughout the life cycle stages which includes determining the system and the system boundary, the system flow chart to determine the various subsystems, collect. organize data, energy discussions.

Improved assessment: Characterization and evaluation of the determined list of the parts to withstand the environmental impact of the process capability.

As the evaluation example, Table 1 shows the $1.0 \times 104$ high-density polyethylene (HDPE) values of energy consumption and environmental burdens regenerator materials. Seen from the table, in the processing stage material, energy consumption and air pollution and water pollution maximum. Therefore, to reduce energy consumption and environmental HDPE regenerator material burden value in its life cycle, it must significantly reduce energy consumption and environmental burdens in the processing stage. table 1 also shows the $1.0 \times 104$ equal-volume environments Storage energy consumption and environmental load material as a contrast value, is clearly much smaller energy consumption and environmental burdens the environment cold accumulating material.

Tab.1 Energy Consumption and Environmental Burden of $1.0 \times 104$

\begin{tabular}{|l|l|l|l|l|}
\hline Project & Air Pollutants & Water Pollutants & Solid contaminants & Energy consumption \\
\hline Raw material & & & & \\
Development & 16.4 & 3.1 & 0.01 & 1.40 \\
Machining & & & & \\
Transport & 56.3 & 5.0 & 0.30 & 52.19 \\
Discard & 4.2 & 0.4 & 0.00 & 1.99 \\
Total & 1.0 & 0.1 & 7.72 & 0.48 \\
Environment Storage & 77.8 & 8.6 & 8.03 & 56.05 \\
Materials & 25.3 & 4.7 & 0.79 & 21.73 \\
& & & & \\
& & & & \\
\hline
\end{tabular}

\section{Looking environmental regenerator material used in cold chain logistics field}

Environmental regenerator material as a new, environmentally friendly, high-quality thermal storage material has important applications significance. Demand for sustainable use of the material when the physical properties of common materials to reduce excessive pollution, it has greater sustainability and prolonged release of cold, cold chain logistics products to meet the refrigerated transport. 

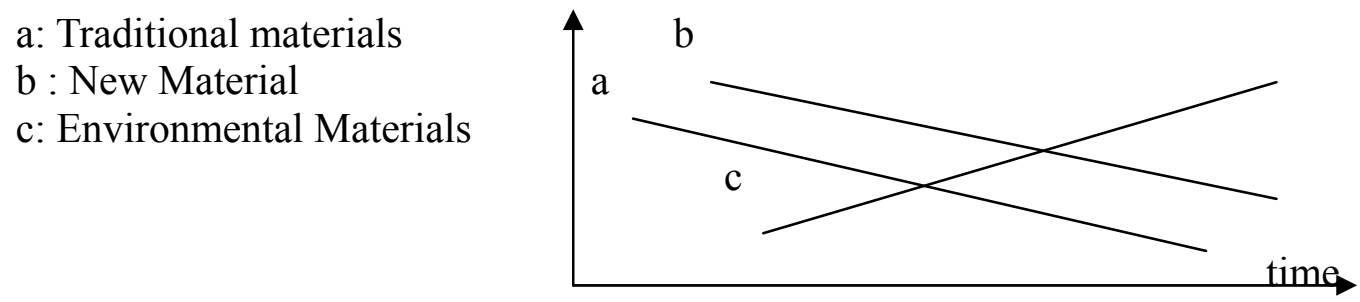

Fig.3 The importance of various materials

\section{Conclusion}

Cold chain products are a special class of products with fresh life, with many kinds of perishable, storage conditions is difficult to grasp, difficult to transport, etc. seeking targeted storage facilities, logistics, materials and conditions to solve their mining important technique after declining quality of logistics. Environmental Materials is the only way for the development of the material, but also the inherent requirements of sustainable development and an important part of the life cycle assessment (LCA) is a new field of study, it is constantly being improved and perfected in practice. Sustainable development is closely related to the material and the environment and achieve sustainable development must vigorously strengthen the research environment of the material. Environmental regenerator material is a new,low-carbon, energy-saving new energy materials, thermal storage system is simple, with excellent storage / release of cold and thermal properties characteristic of phase change latent heat, release cold time extension, made into cold storage logistics chain in the cold storage medium, applied to the cold chain logistics process, has great value.

\section{References}

[1] Wang Bolu.The difficulty and realistic way of sustainable development [J]. World environment, 1998 (2):31-34.

[2] Zuo Tieyong, Weng Rui. Abroad research progress and development trend of environmental materials [J]. Materials guides. 1997(5): $1-4$.

[3] Liu Jianglong, Li Hui , Ding Peidao, Engineering materials of the environmental impact assessment study [J]. Journal of environmental science, 1999 (2):97-102.

[4] Xiao Dingjin, Wang Yongchuan. The technical framework of material cycling system (LCA) assessment [J]. Materials review, 1995 (3):12-13.

[5] Wang Shoubing, Yang Jianxin, Hu dan. The method of cycling life assessment method and its progress [J]. Shanghai environmental science, 1998 (11):7-10

[6] Shan Benliang, Wang Tianmin. Introduction to environmental materials [M]. Beijing: chemical industry press, 1997.

[7]ISO. ISO/CD/14040: Life Cycle Assessment-Principles and Guidelines[S ]. Geneva: International Organization for Standan dization, 1997.

[8] W. Strunk Jr., E.B. White, The Elements of Style, third ed., Macmillan, New York, 1979. 